\title{
ESTRUTURAÇÃO TOPOLÓGICA DE GRANDES BASES DE DADOS DE BACIAS HIDROGRÁFICAS ${ }^{1}$
}

\author{
Carlos Antonio Alvares Soares Ribeiro², Vicente Paulo Soares ${ }^{2}$, Ronaldo Medeiros dos Santos ${ }^{3}$ e Carlos \\ Pedro Boechat Soares ${ }^{2}$
}

\begin{abstract}
RESUMO - O presente trabalho teve como objetivo avaliar o método para delimitação da bacia de contribuição à montante de um ponto selecionado sobre o hidrografia e a obtenção das respectivas características morfométricas, a partir de bases de dados estruturadas topologicamente. Para tanto, utilizou-se o aplicativo Hidrodata 2.0, desenvolvido para o ArcINFO workstation, comparando os seus resultados com os do processo convencional. Os resultados comprovaram que o tempo de processamento demandado para delimitação de bacias e extração de suas características morfométricas a partir de uma base de dados estruturada topologicamente se manteve baixo e constante. Concluiu-se que o método apresentado poderá ser aplicado em qualquer bacia hidrográfica, independentemente do seu tamanho, mesmo com o uso de computadores de configuração mais modesta.
\end{abstract}

Palavras-chave: Bacia Amazônica, estruturação topológica e modelos digitais de elevação hidrologicamente consistentes.

\section{TOPOLOGICALLY-STRUCTURED LARGE DATASETS FOR WATERSHEDS}

\begin{abstract}
The present work aims to present and to evaluate a method for topologically structuring large databases, implemented as a set of AML routines for ArcINFO workstation named Hidrodata. The results proved that the processing time for delineating drainage areas and extracting their morphometric characteristics was kept low and constant. The use of a topologically structured database resulted in a lower demand of processing capacity. It was concluded that the presented approach can be applied for any watershed, independently of its size, even with the use of less-sophisticated computers.
\end{abstract}

Keywords: Amazon basin, topologically structured datasets, hydrographically-conditioned digital elevation models.

\section{INTRODUÇÃO}

A delimitação de uma bacia hidrográfica é um dos primeiros e mais comuns procedimentos executados em análises hidrológicas ou ambientais. Para isso, é comum utilizarem-se informações de relevo em formato analógico, como mapas e cartas, o que compromete a confiabilidade e reprodução dos resultados devido à carga de subjetividade inerente aos métodos manuais (MARTZ e GARBRECHT, 1992; MENDES e CIRILO, 2001).
Com o advento e a consolidação dos Sistemas de Informações Geográficas e, consequentemente, o surgimento de formas digitais consistentes de representação do relevo, como os modelos digitais de elevação (MDE), métodos automáticos para delimitação de bacias têm sido desenvolvidos desde então (GARBRECHT e MARTZ, 1999). No entanto, esses métodos encontraram barreiras à sua plena difusão pelo fato de demandarem considerável poder

\footnotetext{
${ }^{1}$ Recebido em 31.10.2006 e aceito para publicação em 19.05.2008.

${ }^{2}$ Departamento de Engenharia Florestal da Universidade Federal de Viçosa(UFV), Viçosa-MG. E-mail: <cribeiro@ufv.br>e<vicente@ufv.br> .

${ }^{3}$ Programa de Pós-Graduação em Ciência Florestal da UFV.
} 
computacional, notadamente, em se tratando de estudos de grandes áreas, uma vez que o tempo de processamento aumenta à medida que aumenta o tamanho da área a ser delimitada (PEREZ, 1999).

O aumento da demanda por instrumentos de suporte à gestão dos recursos hídricos torna patente a necessidade de geração de novos métodos para essa finalidade. Esses instrumentos consistem em técnicas e estudos de quantificação, enquadramento, prevenção e controle de eventos extremos, manejo e conservação de bacias, dentre outros, que se utilizam de um conjunto comum de informações derivadas para a respectiva bacia (BRASIL, 2001; RIBEIRO et. al, 2003). Tais informações devem ser acessíveis ao maior número de usuários possível, além de proporcionarem facilidade de reprodução e conexão a outras fontes de dados, possibilitando a construção de sistemas integrados de informação e gestão em recursos hídricos (BRASIL, 1997).

O aplicativo Hidrodata $2.0^{4}$, desenvolvido em AML (Arc Macro Language) para o ArcINFO workstation, contém recursos específicos para estruturar topologicamente grandes bases de dados digitais de bacias hidrográficas bem como para extrair a bacia de contribuição, a respectiva rede de drenagem e as características morfométricas (área, perímetro, fator de forma, comprimento total dos cursos d'água, densidade de drenagem, comprimento e declividade do maior curso d'água, distância da extremidade de cada segmento à foz da bacia) à montante de qualquer ponto situado ao longo da hidrografia.

O objetivo do presente trabalho foi avaliar a eficiência da técnica de estruturação topológica, comparandose os tempos de extração das informações utilizandose o Hidrodata 2.0 com os resultados obtidos pela abordagem tradicional. Para tanto, gerou-se uma série de 1000 pontos distribuídos aleatoriamente ao longo da rede de drenagem da área de estudo.

\section{MATERIAL E MÉTODOS}

A área de estudo compreendeu a bacia de contribuição à montante da estação fluviométrica Fazenda Borangaba, situada no Rio Pauini, afluente do Rio Purus, no Estado do Amazonas, de aproximadamente 23.340 $\mathrm{km}^{2}$, conforme ilustra a Figura 1.

${ }^{4}$ A ser disponibilizado no site da SIF.

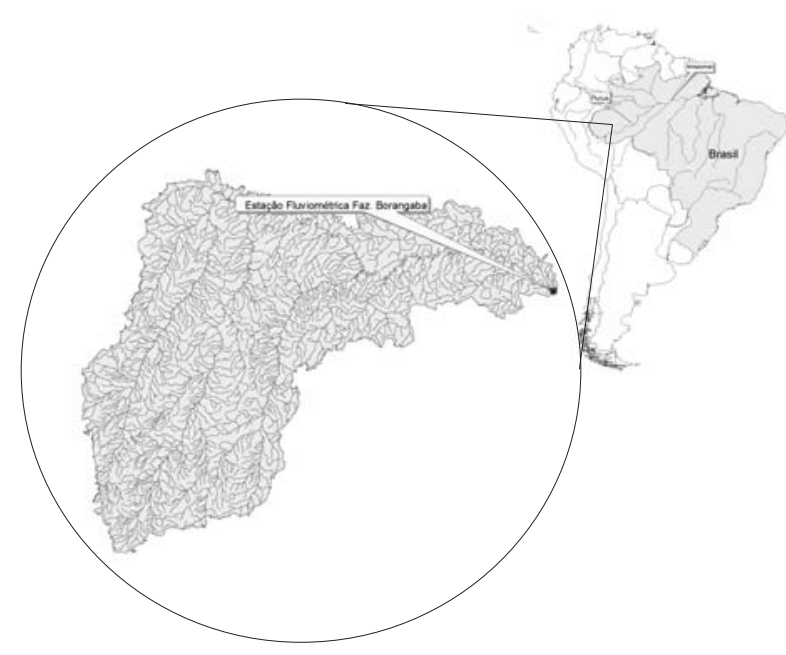

Figura 1 - Localização da área de estudo. Figure 1 - Study area.

Utilizou-se uma estação de trabalho com processador Pentium III Xeon, 931 Mhz e memória RAM de 512 $\mathrm{Mb}$, equipada com os softwares Arc/INFO workstation 8.3, para aplicação do método automático tradicional, e o Hidrodata 2.0, para estruturação topológica e delimitação de bacias a partir da base estruturada.

A base de dados utilizada foi disponibilizada pelo convênio SIF/SIVAM/UFV “Geração de Modelos Digitais de Elevação Hidrologicamente Consistentes (MDEHC) para a Região Amazônica brasileira” e consistiu nos grids: modelo digital de elevação, rede hidrográfica, direções de escoamento e fluxo acumulado, todos com tamanho de célula igual a 50m.

\subsection{Estruturação topológica}

A natureza organiza-se geograficamente em termos de bacias hidrográficas. A estrutura dessa organização é altamente eficiente pois não existem lacunas ou superposições; ao contrário, as unidades menores se combinam topologicamente, de uma forma aninhada, para originar bacias maiores, iniciando-se pelas bacias de cabeceira e caminhando em direção à foz do respectivo curso d’água. Todas as regras existentes para as bacias de cabeceira, isto é, bacias sem tributários, são naturalmente repassadas à estrutura maior subseqüente. Uma análise mais detida sobre essa estratégia de organização informacional torna patente que a bacia 
hidrográfica é uma estrutura elementar naturalmente adequada à organização, ao armazenamento, às análises espaciais e à disseminação de um conjunto de informações hidrológicas. Essa constatação vai de encontro à tradição cartográfica de organizar o espaço em parcelas retangulares adjacentes: os mapas. Porquanto para a grande maioria das aplicações os mapas analógicos tenham facilitado sobremaneira a organização de acervos ao longos dos séculos, é inegável que tal estrutura mostra-se inadequada aos estudos hidrológicos, que têm por limite a bacia hidrográfica. $\mathrm{O}$ amadurecimento da tecnologia dos sistemas de informações geográficas permitiu romper definitivamente com esse modelo tradicional, viabilizando hoje a estruturação de bases de dados contínuas.

A questão fundamental que norteou o desenvolvimento da metodologia do presente trabalho foi: como replicar a simplicidade e a eficiência da natureza na organização da informação geográfica?

A chave para responder essa pergunta está na análise dos relacionamentos topológicos (implícitos) existentes entre os elementos geométricos que representam as feições básicas de uma bacia hidrográfica: pontos, linhas e polígonos. As nascentes, as confluências e a foz de uma rede hidrográfica podem ser convenientemente representadas por pontos. Os trechos da rede hidrográfica podem ser representados por linhas. Há, entretanto, uma associação óbvia entre os pontos e as linhas: cada segmento da hidrografia inicia-se em um ponto (uma nascente ou uma confluência) e termina em outro ponto (outra confluência ou uma foz). Considerando-se o sentido do fluxo da água, cada segmento terá então uma origem e um destino. Por outro lado, cada segmento da rede de drenagem drena uma certa área; essa área define, assim, a bacia de drenagem associada ao segmento, sendo convenientemente representada por um polígono. Dado que todo o escoamento das águas superficiais dentro dessa região convergirá, necessariamente, para a extremidade inferior (confluência ou foz) do segmento da hidrografia, percebe-se também que existe uma associação natural entre a área de drenagem e seu exutório.

No ponto de confluência de dois cursos d’água, a respectiva bacia de contribuição é dada pela união da área de drenagem associada a cada curso d’água. A materialização da bacia de drenagem assim resultante requer a geração de um novo polígono, criado pela remoção da linha associada ao divisor de águas comum às duas áreas de drenagem. O perímetro desse polígono representa o divisor de águas dessa bacia de drenagem. À medida em que se percorre a rede hidrográfica em direção à sua foz, a cada nova confluência haverá a necessidade de se criar um novo polígono descrevendo a respectiva área de drenagem. Esse novo polígono engloba (aninha) todos os polígonos associados às áreas de drenagem de todos os trechos da rede hidrográfica situados à montante da confluência em questão.

Processo semelhante ocorre com os trechos da hidrografia: para cada confluência combinam-se os trechos da rede hidrográfica situados à montante da confluência para indicar a respectiva rede de drenagem associada àquele ponto. A esse processo de agregações sucessivas dá-se o nome de aninhamento.

A tentativa de se representar cada nível de aninhamento, tanto para a rede hidrográfica quanto para as sub-bacias, utilizando-se os procedimentos convencionais de criação de dados digitais, mostrase impraticável pois as respectivas bases de dados conterão um número consideravelmente maior de feições que as bases originais. Para contornar esse problema, lançou-se mão de dois tipos especiais de feições, existentes no ArcINFO workstation: rotas e regiões. As rotas são criadas a partir de um conjunto de arcos, prestando-se perfeitamente à representação de cada nível de aninhamento da hidrografia. Já as regiões são criadas com base em polígonos, sendo adequadas às representações dos diversos níveis de aninhamentos das áreas de drenagem.

A grande vantagem de se utilizarem rotas e regiões ao invés de linhas e polígonos é que essas feições não replicam as informações espaciais que lhes deram origem, apenas mantêm um vínculo com elas. Para cada nível de aninhamento haverá um registro correspondente na respectiva tabela de atributos (rotas ou regiões), descrevendo suas propriedades (comprimento; área, perímetro). Essa estratégia de organização topológica da rede hidrográfica e das respectivas áreas de drenagem foi a base para o desenvolvimento do aplicativo Hidrodata.

\subsubsection{Extração de informações dos arcos e nós por caminhamento em redes}

A estruturação topológica da base de dados da área de estudo foi efetuada utilizando-se o Hidrodata

R. Árvore, Viçosa-MG, v.32, n.4, p.687-696, 2008 
2.0. e consistiu na extração e organização das informações morfométricas da rede e das áreas de drenagem em ambiente georrefenciado, utilizando-se das relações existentes entre os elementos geométricos que representam as feições básicas de uma bacia hidrográfica: pontos, linhas e polígonos. Aplicaram-se para essa finalidade, os recursos de caminhamento em redes, disponíveis no módulo Network do ArcINFO. A interface principal do Hidrodata 2.0 é apresentada na Figura 2.

Nessa tela, há três blocos de comandos: um para se especificarem as bases de dados raster (grids de entrada); outro para criação de uma base de dados topologicamente estruturada a partir dos grids selecionados na etapa anterior; e um terceiro conjunto, para delimitação da bacia de contribuição e da sua rede de drenagem, seguidas da obtenção das respectivas características morfométricas. A especificação do(s) ponto(s) de interesse no Hidrodata poderá ser feita de três maneiras: i) por seleção visual, tendo-se por base a rede de drenagem, ii) informandose as suas coordenadas X,Y, e iii) fornecendo-se uma base de dados vetorial contendo a localização e a identificação do(s) ponto(s).

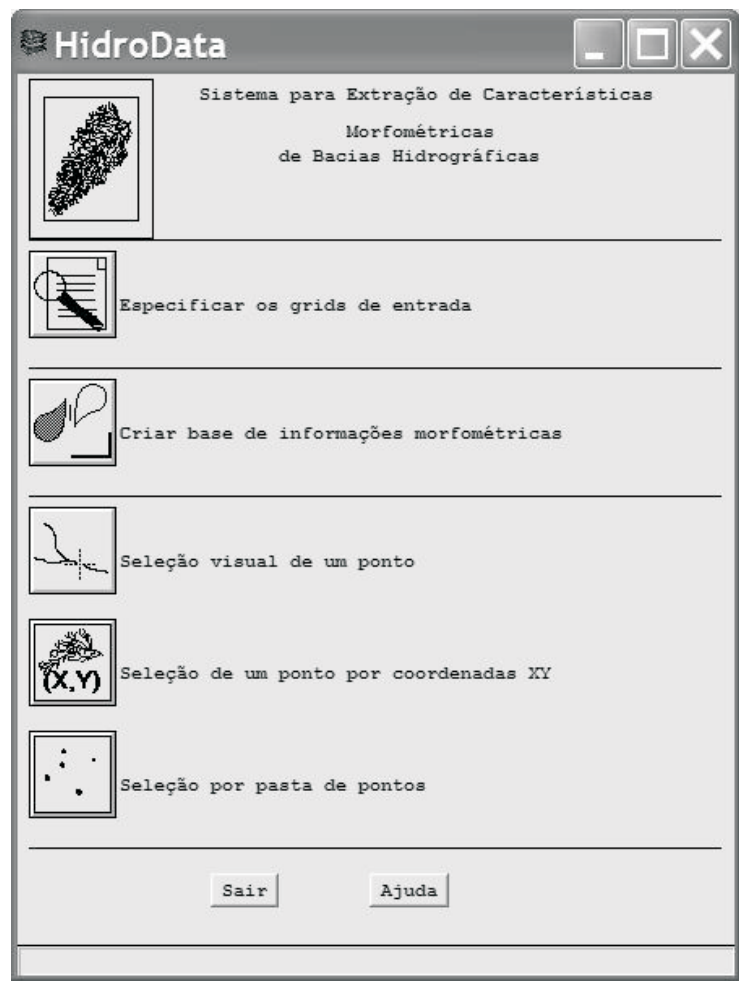

Figura 2 - Tela principal do Hidrodata 2.0. Figure 2 - Main menu of Hidrodata 2.0.

R. Árvore, Viçosa-MG, v.32, n.4, p.687-696, 2008
O comando TRACE UPSTREAM foi utilizado para identificar o conjunto de arcos da rede de drenagem à montante de um ponto da bacia analisada enquanto que, com o uso do TRACEACCUMULATE, foram obtidos o comprimento acumulado dos arcos no sentido das cabeceiras (distância de cada nó à foz da bacia), o comprimento acumulado dos arcos no sentido da foz (comprimento total da rede de drenagem à montante da foz do arco) e o número de ordem de cada segmento segundo o método de SHREVE (1967). Tais informações foram armazenadas nas tabelas de atributos criadas pelo comando TRACE, mantendo-se um vínculo com os identificadores dos arcos e dos nós.

\subsubsection{Extração das informações morfométricas para a rede de drenagem}

Por meio da criação de rotas, podem-se definir atributos para um conjunto de arcos ou para um determinado trecho de um arco simples. Os pontos de início e fim de uma rota não precisam necessariamente coincidir com o início e fim de um arco (ESRI, 2002). As rotas são construídas utilizando-se os recursos de segmentação dinâmica disponibilizados no módulo Network do ArcINFO workstation. A técnica de segmentação dinâmica permite que diversas rotas possam ser criadas a partir dos arcos da rede de drenagem sem que se replique a estrutura vetorial dessa base de dados.

Utilizando-se o comando MAKEROUTE, do módulo ARCEDIT, foram geradas rotas individuais para cada segmento de drenagem, rotas para todos os níveis de aninhamento da hidrografia, rotas para os maiores cursos d’água de cada nível de aninhamento, e rotas para os trechos situados entre $10 \%$ e $85 \%$ do comprimento dos maiores cursos identificados, tomando-se como referência a nascente. As informações topológicas e morfométricas pertinentes a cada rota foram devidamente armazenadas nas tabelas de atributos correspondentes.

\subsubsection{Aninhamento das áreas de drenagem}

A forma quadrada das células do grid reflete-se no limite vetorial das bacias. Assim, ao optar-se por manter a fidedignidade entre as representações raster e vetorial, certas bacias poderão ser representadas por múltiplos polígonos conectados pelos seus vértices. A solução adotada no Hidrodata 2.0 para se ter um identificador único associado a cada área de drenagem foi estruturar essa base de dados utilizando-se REGIONS 
para criar feições multipartes. Esse tipo especial de feição do ArcINFO permite agrupar polígonos espacialmente disjuntos em uma única feição, que passa então a se comportar como um único polígono. Por exemplo, selecionando-se qualquer uma de suas partes, todas as demais serão automaticamente selecionadas. A área de uma feição multipartes é igual à soma das áreas individuais de cada uma de suas partes, o mesmo valendo para seu perímetro. Dessa forma, mantem-se a relação biunívoca entre as feições e os registros da respectiva tabela de atributos. À semelhança das rotas, as regiões também não replicam as informações vetoriais dos polígonos das bacias hidrográficas, sendo dinamicamente construídas a partir destes para fins de visualização.

A utilização de feições multipartes para representar as áreas de drenagem possibilita a estruturação topológica das bacias em todos os níveis de agregação, partindo-se da foz e percorrendo toda a rede hidrográfica na direção das suas cabeceiras, aninhando-as sucessivamente, sem que haja replicação das informações espaciais; criam-se tão somente novas tabelas de atributos. Esse procedimento conduz à identificação e ao armazenamento da área de contribuição, assim como das informações morfométricas associadas, e.g., comprimento total da drenagem contida na região, densidade de drenagem e o fator de forma.

\subsection{Delimitação automática de bacias a partir da base estruturada}

Para delimitação da área de contribuição à montante de um ponto de interesse, identifica-se inicialmente o respectivo segmento de drenagem. Todos os polígonos gerados na fase de estruturação topológica, situados imediatamente à montante do topo do referido segmento, já estão identificados e fundidos em um único polígono, armazenado como região.

A área de análise para aplicação do comando Watershed é confinada então à área drenada exclusivamente pelo segmento. Esse procedimento é crucial para se minimizar o tempo de extração das informações. O passo seguinte é identificar a respectiva área de drenagem entre o ponto selecionado e o topo do segmento da hidrografia que o contém. Em seguida, essa área é anexada ao polígono associado à bacia de contribuição do topo do segmento contendo o ponto de interesse, passando assim a compor a área total de drenagem para o ponto especificado.
Para extração da rede hidrográfica o procedimento é semelhante: identifica-se o segmento que contém o ponto, seleciona-se toda a rede de arcos situados à montante (que já está estruturada com uma rota), recorta-se o trecho do segmento localizado entre o ponto e o topo desse segmento e então anexa-se esse trecho à rede de arcos situados à montante do seu topo. Em seguida, identifica-se o maior curso d'água e derivam-se as características morfométricas da rede de drenagem e da área de contribuição.

\subsection{Abordagem tradicional para a delimitação de bacias hidrográficas e extração das respectivas características morfométricas}

O procedimento usual para se delimitar a bacia de contribuição de um ponto qualquer situado ao longo da hidrografia utiliza o comando Watershed do módulo Grid. Esse comando requer, como dados de entrada, o grid das direções de escoamento e a célula associada à localização do ponto sobre a rede hidrográfica. $\mathrm{O}$ tempo de processamento é diretamente proporcional à área da bacia de contribuição. Assim, pontos próximos às cabeceiras demandarão menos tempo que aqueles situados próximos à foz de uma dada bacia hidrográfica.

A extração da rede hidrográfica à montante do ponto é feita simplesmente recortando-se a rede de drenagem com o polígono da bacia de contribuição do ponto. Já a identificação do maior curso d’água à montante do ponto especificado requer a utilização do módulo Network do ArcINFO, que dispõe de recursos específicos para caminhamento de redes.

Considerando-se a grande quantidade de pontos utilizados para a comparação de desempenho entre as duas abordagens, a seqüência de comandos para obtenção das informações pelo método tradicional foi então codificada em AML, dando origem à rotina Extrai_Normal.

\subsection{Comparação do tempo de processamento para as duas abordagens}

Criou-se uma base de dados contendo 1000 pontos selecionados aleatoriamente ao longo da porção da rede hidrográfica do Rio Pauini situada à montante da estação fluviométrica Fazenda Borangaba.

A identificação da bacia de contribuição e da rede hidrográfica e a obtenção das respectivas características morfométricas, para cada um desses 1000 pontos, foram efetuadas tanto pela abordagem convencional

R. Árvore, Viçosa-MG, v.32, n.4, p.687-696, 2008 
(Extrai_Normal) quanto pela estruturação topológica (Hidrodata 2.0), registrando-se o tempo de execução e o número de células de cada bacia delimitada.

\section{RESULTADOS E DISCUSSÃO}

\subsection{Estruturação topológica da base de dados}

A Figura 3 ilustra três seleções efetuadas em uma rede de drenagem: duas para pontos (uma cabeceira e uma confluência) e outra para um arco (trecho sem tributários), assim como as informações topológicas armazenadas em suas respectivas tabelas de atributos ao final do processo de estruturação.

\subsection{1 - Geração das informações morfométricas para a drenagem}

O processo de criação de rotas aninhadas para a rede hidrográfica é ilustrado na Figura 4, enquanto que as figuras 5, 6 e 7, ilustram as rotas geradas para armazenar as informações extraídas para uma sub-bacia, para o curso d’água principal, e para o trecho 10-85, respectivamente.

\subsubsection{Aninhamento topológico e extração das informações morfométricas}

O resultado da aplicação de regiões no tratamento de bacias 1441 e 1444, formadas por múltiplos polígonos devido ao processo de conversão do formato raster para o formato vetorial, é apresentado pela Figura 8.

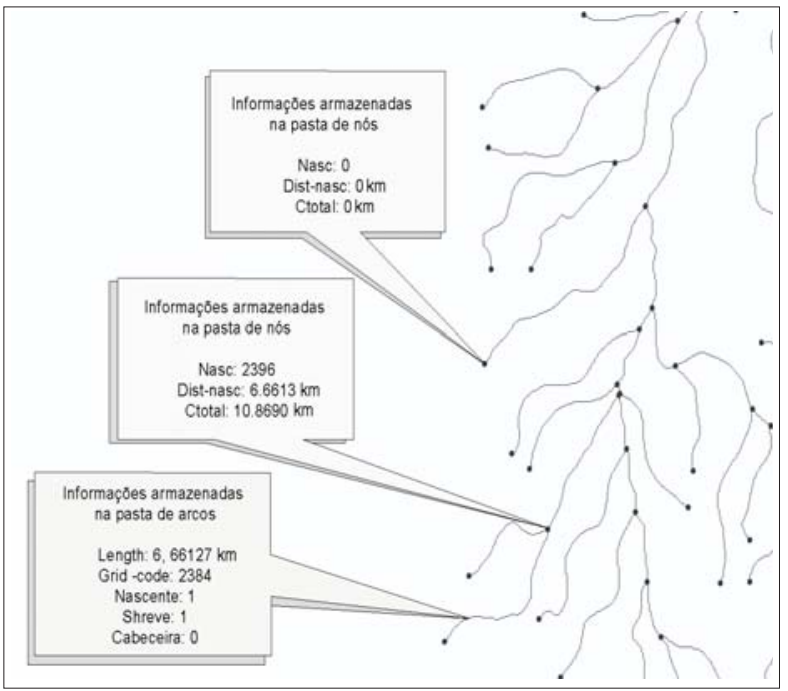

Figura 3 - Informações geradas para as pastas de arcos e nós. Figure 3-Information generated for the arc and node coverages.

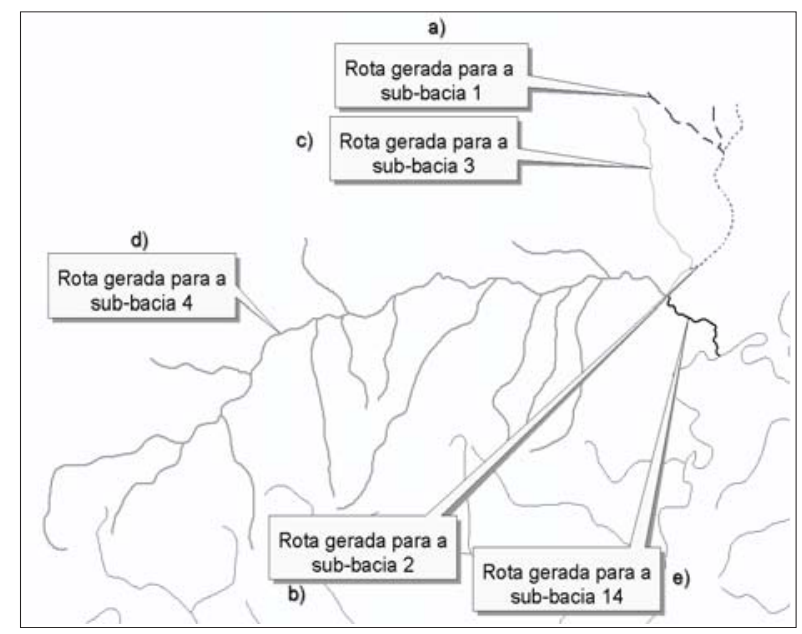

Figura 4-Processo de geração de rotas para a rede de drenagem. Figure 4-Generation of routes for the stream network.

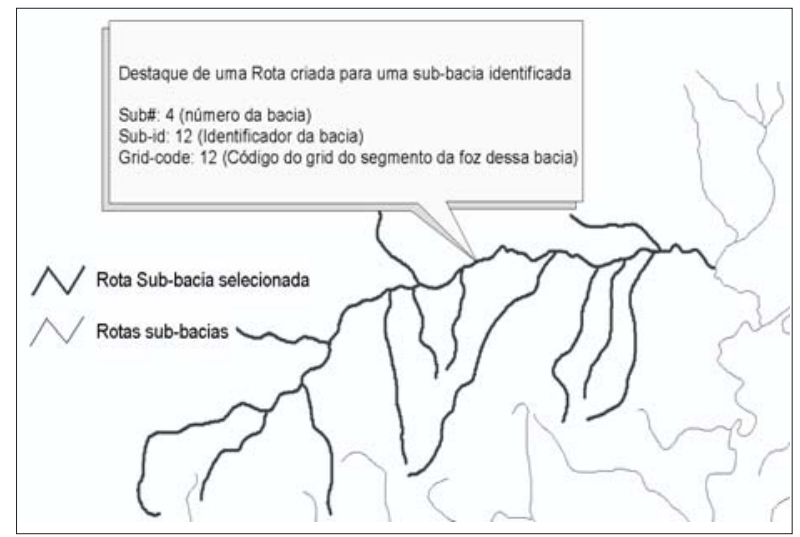

Figura 5 - Rota gerada para a drenagem de uma sub-bacia. Figure 5-Route generated for a sub-basin's stream network.

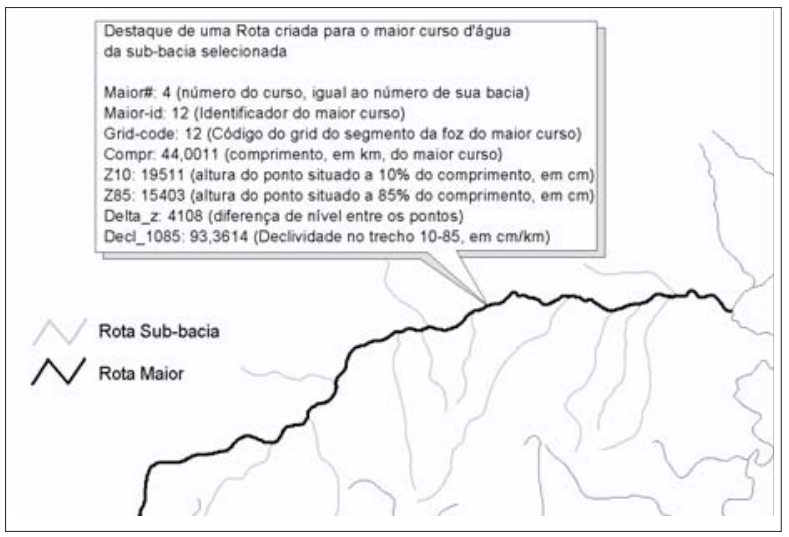

Figura 6 - Rota gerada para o curso principal de uma sub-bacia. Figure 6 - Route generated for the main course of a sub-basin. 


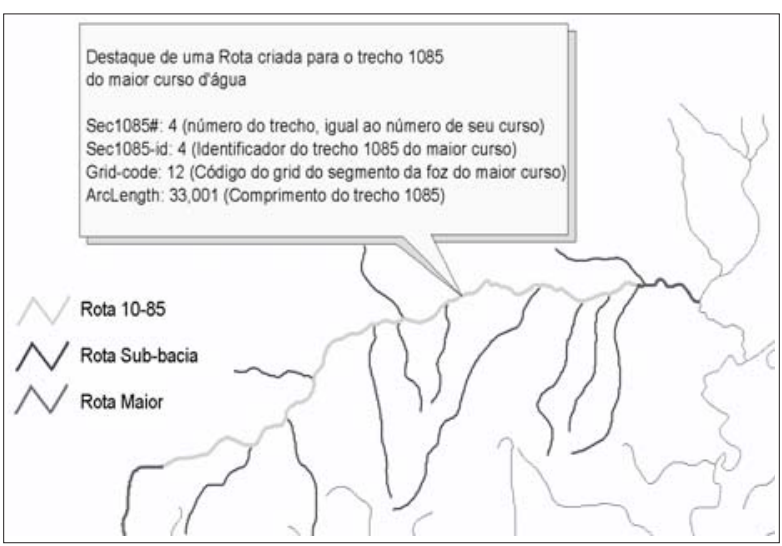

Figura 7-Seção 10-85 do curso d'água principal de uma sub-bacia. Figure 7 - Section 10-85 of the main course of a sub-basin.

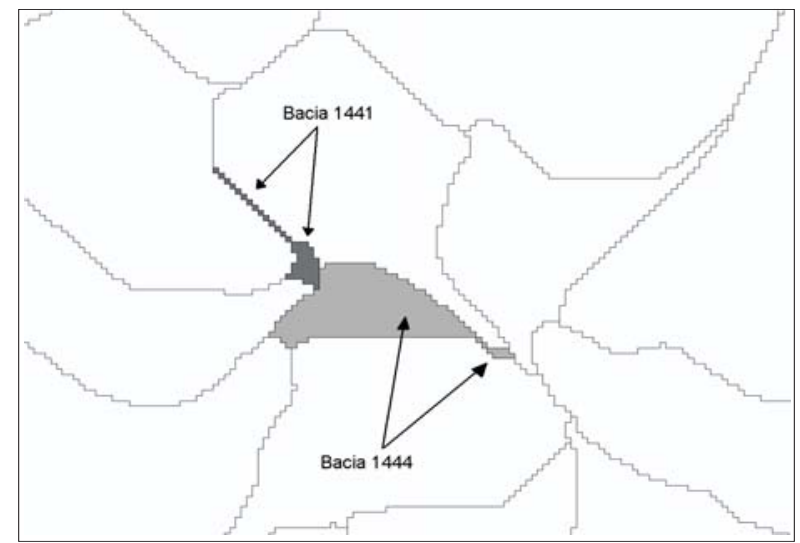

Figura 8 - Regiões geradas para bacias formadas por múltiplos polígonos.

Figure 8 - Regions generated for catchments formed by multiple polygons.

As regiões foram geradas segundo o aninhamento natural das bacias; daquelas de cabeceira às bacias subseqüentes, até a foz da maior bacia identificada (bacia da área de estudo). A Figura 9 ilustra o resultado do processo de aninhamento para geração das regiões associadas às bacias.

Para cada segmento de drenagem foram geradas três regiões: uma representando a área drenada exclusivamente pelo segmento, uma para a área de drenagem situada à montante da nascente do segmento e uma para a área de drenagem imediatamente à montante da foz do segmento. Caso a bacia de interesse corresponda à área de contribuição à montante de uma confluência, as informações já se encontram disponíveis nas regiões, conforme ilustra a Figura 10.

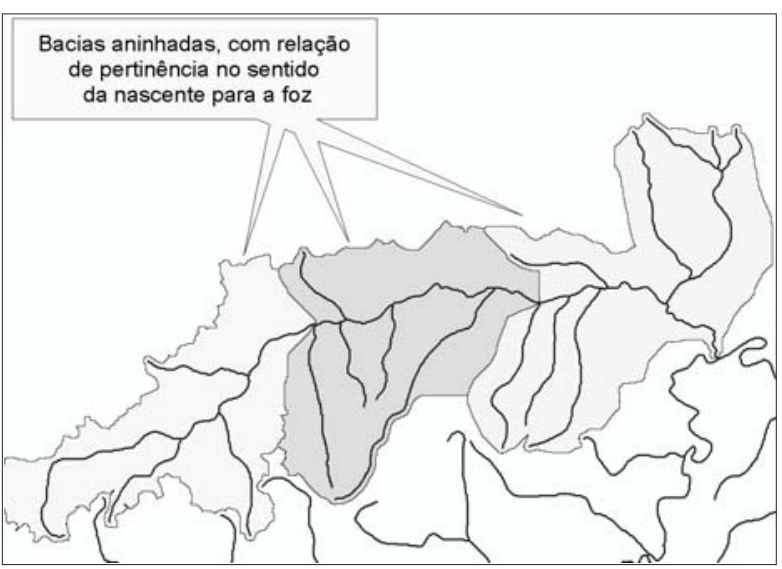

Figura 9 - Seqüência do processo de aninhamento, até a foz do segmento 30 .

Figure 9 - Sequence of the nesting process, until the end of the segment 30 .

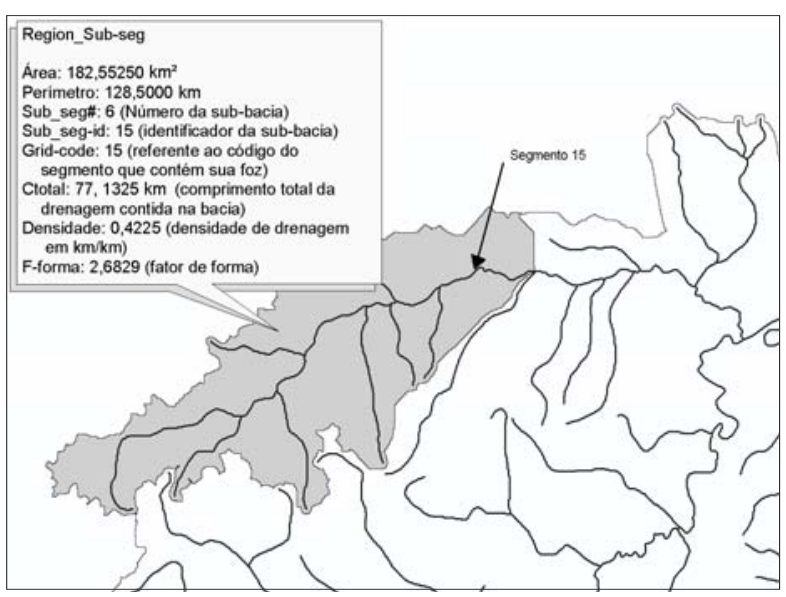

Figura 10 - Região para a área total de contribuição de um segmento.

Figure 10 - Region for the total drainage area of a given segment.

\subsection{Delimitação automática de bacias - base topologicamente estruturada}

Como principal resultado da estruturação topológica da base de dados, tem-se que as operações subseqüentes de delimitação de bacias e extração de suas características morfométricas foram extremamente otimizadas, havendo pequena variação no tempo de extração em relação ao tamanho da bacia extraída (da ordem de segundos). As figuras 11, 12, 13 e 14 ilustram a seqüência para delimitação e extração das características morfométricas de uma bacia, para um ponto qualquer da drenagem.

\section{sitif}

R. Árvore, Viçosa-MG, v.32, n.4, p.687-696, 2008 


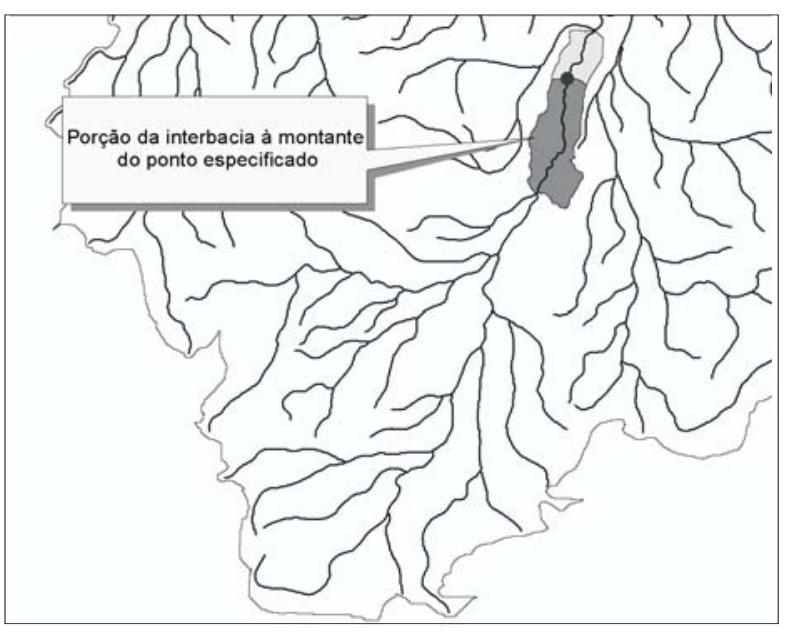

Figura 11 - Extração da bacia imediatamente à montante do ponto especificado.

Figure 11 - Extraction of the basin immediately upstream of the specified point.

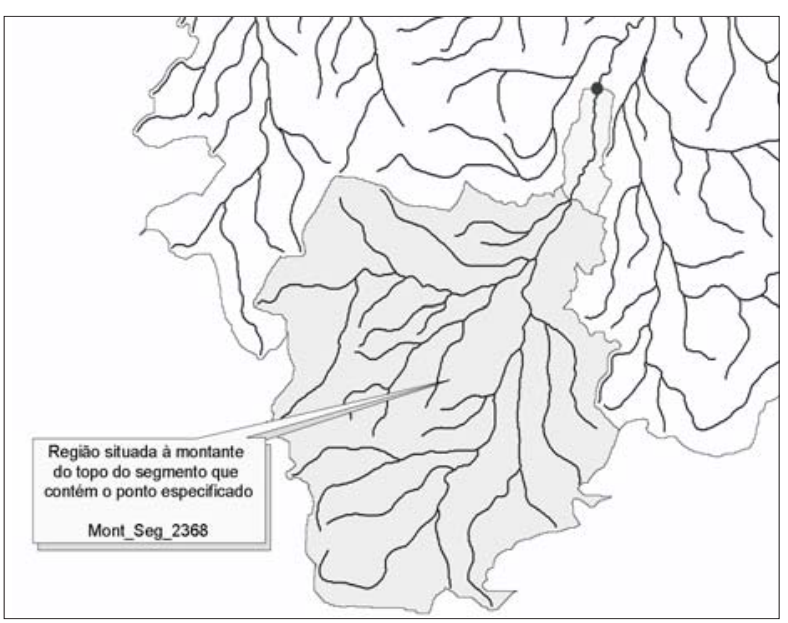

Figura 12 - Região localizada à montante do segmento que contém o ponto.

Figure 12-Region located upstream of the segment containing the point.

\subsection{Comparação dos tempos de processamento entre os dois métodos}

Observando-se separadamente o tempo demandado por cada processo, verificou-se que as maiores contribuições ao tempo total gasto, pelas duas metodologias, foram as operações efetuadas para extração da bacia de contribuição.

As figuras 15 e 16 apresentam as curvas “Tempo de processamento x Número de Células” para o método tradicional e para a base topologicamente estruturada, respectivamente, podendo-se observar, em primeira instância, a ordem de grandeza dos tempos e a variação dos mesmos, para incrementos no número de células, para os dois métodos. O método tradicional apresentou valores de tempo situados entre 26 e 750 segundos, com tendência de crescimento de acordo com o aumento no número de células (área) da bacia delimitada, confirmando as observações de Djokic e Ye (2000), e Perez (1999) a respeito desse fato (Figura 15).

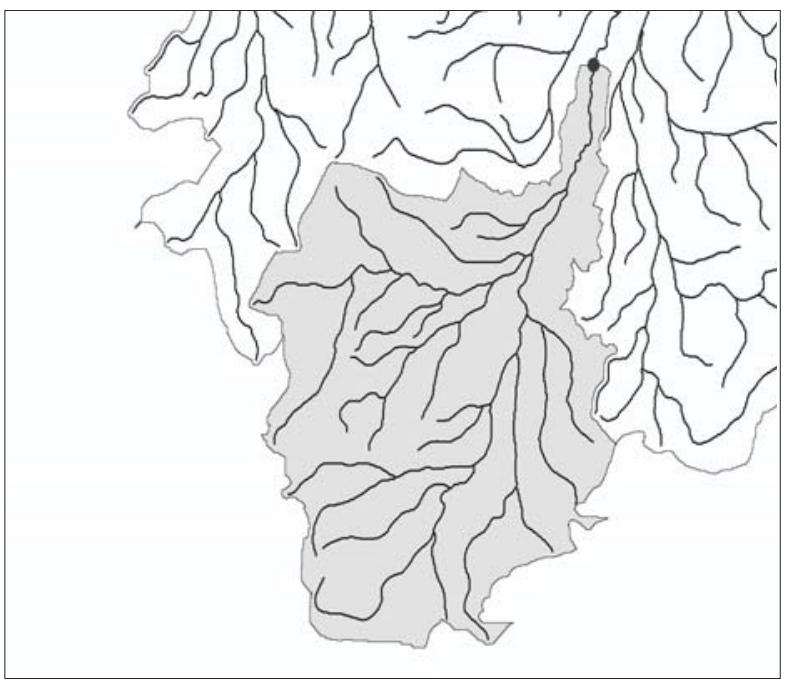

Figura 13 - Fusão dos dois polígonos.

Figure 13-Merging the two polygons.

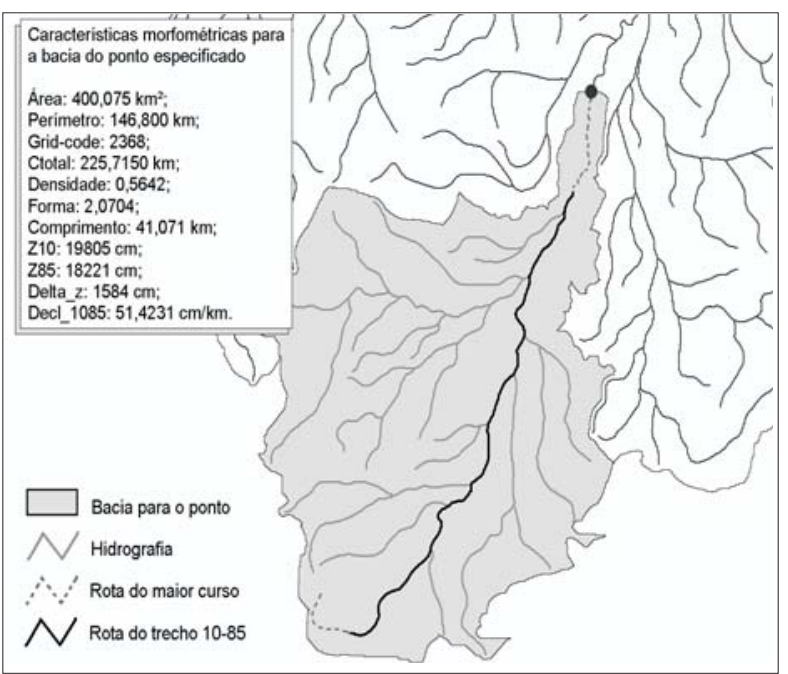

Figura 14 - Resultado final: bacia e suas características morfométricas.

Figure 14-Final result: basin and its morphometric characteristics. 
Para a base topologicamente estruturada, o tempo de delimitação variou de 4 a 21 segundos, com um rápido crescimento até os 15 segundos, para bacias com até 25.000 células. Daí em diante, o tempo de processamento permaneceu estável para bacias com até 5 milhões de células, para então indicar um ligeiro aumento para bacias com áreas situadas entre 7 e 9 milhões de células (Figura 16).

O desempenho do método de estruturação topológica se explica pelo fato de que a área de análise é mantida aproximadamente constante e com tamanho reduzido, quando comparada à área completa a ser extraída ao final. Isso é conseguido graças à configuração do ambiente de análise para aplicação do WATERSHED, restringindoo apenas à área de drenagem associada ao segmento que contém o ponto. As descontinuidades observadas nas curvas das figuras 15 e 16 são devidas à não existência de bacias com número de células situadas nessa região. Isto se explica pelo seguinte fato: ao ocorrer o encontro de dois cursos d’água, a área de drenagem é significativamente aumentada, ocasionando "saltos" de valores para os pontos localizados imediatamente à jusante de confluências entre dois grandes rios.

A variação observada no tempo para extração das bacias, segundo esse método, pode ser explicada pela variação na área das bacias de cabeceira e pela localização das mesmas na área de estudo, em relação ao sentido padrão de cálculo em ambiente raster no ArcINFO, i.e., varredura da esquerda para a direita e de cima para baixo.

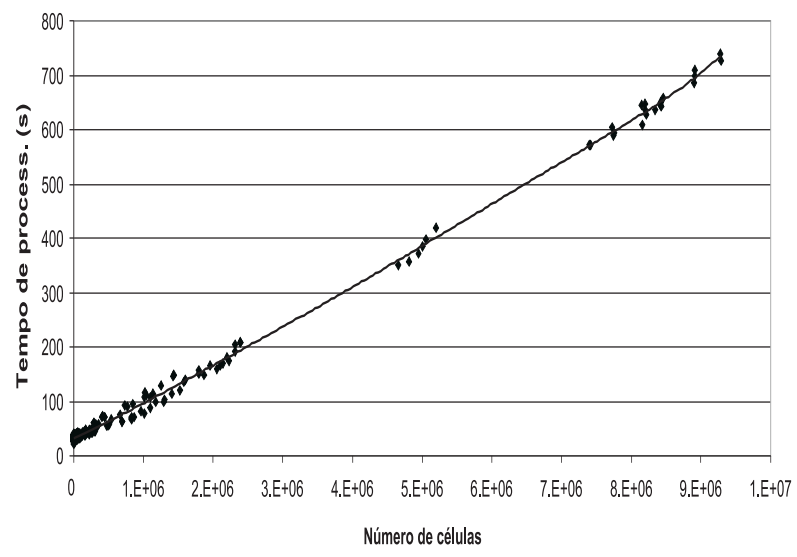

Figura 15 - Tempo de processamento x Número de Células - método Tradicional.

Figure 15-Processing time x cell number - Traditional method.

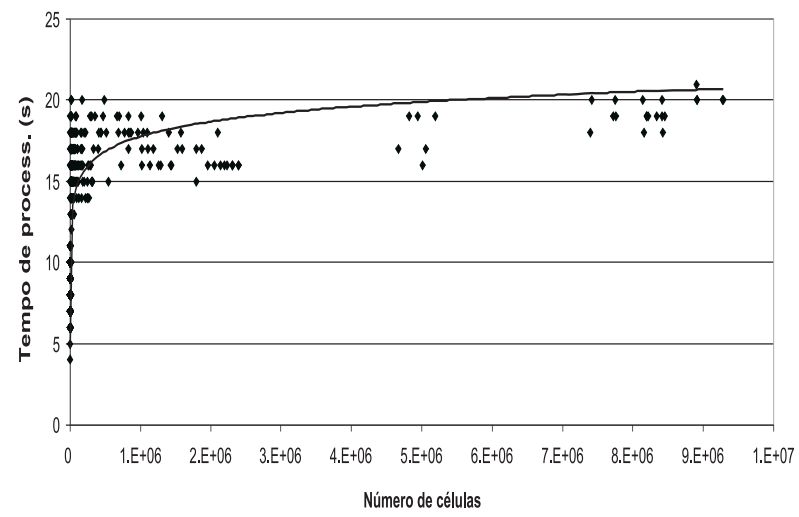

Figura 16 - Tempo de processamento x Número de Células - estruturação topológica.

Figure 16 - Processing time x cell number - topologicallystructured database.

\section{CONCLUSÕES}

Ainda que haja uma certa variação no tamanho das sub-bacias, efetivamente o processo de extração da área de contribuição estará confinado espacialmente a uma região bastante pequena quando comparada à extensão total da base de dados. Pode-se, assim, concluir que o desempenho da metodologia apresentada é, para efeitos práticos, invariante em relação ao tamanho (número de células) do grid.

O desenvolvimento e a implementação dessa metodologia, sob a forma de um aplicativo (HidroData 2.0) representam considerável avanço e solucionam as principais limitações dos métodos tradicionais de derivação, armazenamento, gerenciamento e disponibilização de grandes bases de dados de bacias hidrográficas, viabilizando tais análises em tempo real utilizando computadores de desempenho razoável. Criamse, assim, as condições necessárias para o oferecimento desses serviços via internet.

\section{REFERÊNCIAS BIBLIOGRÁFICAS}

BRASIL, Lei Federal no ${ }^{\circ}$.433, de 8 de Janeiro de 1997. Institui a política nacional dos recursos Hídricos. Brasília, 1997. 15p. Disponível em <http:/ /www.aneel.gov.br/cedoc /lei1997-9433.pdf > . Acesso em: 20 maio 2004.

BRASIL, Agência Nacional de Águas - ANA. Anexo 1: Demandas tecnológicas da ANA, 2001. 6p. Disponível em <http://ana.gov.br/ gestaorechidricos/tecnologiacapacitacao/docs/ relatorios/rec-anexo1.pdf> . Acesso em: 20 maio 2004.

R. Árvore, Viçosa-MG, v.32, n.4, p.687-696, 2008 
DJOKIC, D.; YE, Z. DEM Preprocessing for efficient watershed delineation. Redlands, ESRI Press. 2000. 10p.

ESRI - Environment Systems Research Institute. Introducing network (ArcInfo Help, v8.3). Redlands, CA, 2002.

GARBRECHT, J.; MARTZ, L.W. Digital elevation model issues in water resources modeling, Proceedings of the 19th ESRI Users Conference, San Diego, CA, 1999.

MARTZ, L.W.; GARBRECHT, J. Numerical definition of drainage network and subcatchment areas from digital elevation models. Computers and Geosciences, 18(6):747-761, 1992.
MENDES, C.A.B.; CIRILO, J.A. Geprocessamento em recursos hídricos: princípios e aplicação. 1 ed. Porto Alegre, ABRH, 2001. 536p.

PEREZ, A. Source water protection project: a comparison of watershed delineation methods in Arc/INFO and ArcView, Proceedings of the 19th ESRI Users Conference, San Diego, CA, 1999.

RIBEIRO, C.A.A.S.; SOARES, V.P; CHAVES, M.A.; EUCLYDES, H.P. Metodologia para Geração de Modelos Digitais de Elevação Hidrologicamente Consistentes para a Bacia Amazônica. I Simpósio de Recursos Hídricos da Amazônia, 2003, Manaus, p. 1-9.

SHREVE, R. L. Infinite topological random channel networks, Journal of Geology, 75: 178-86. 1967. 